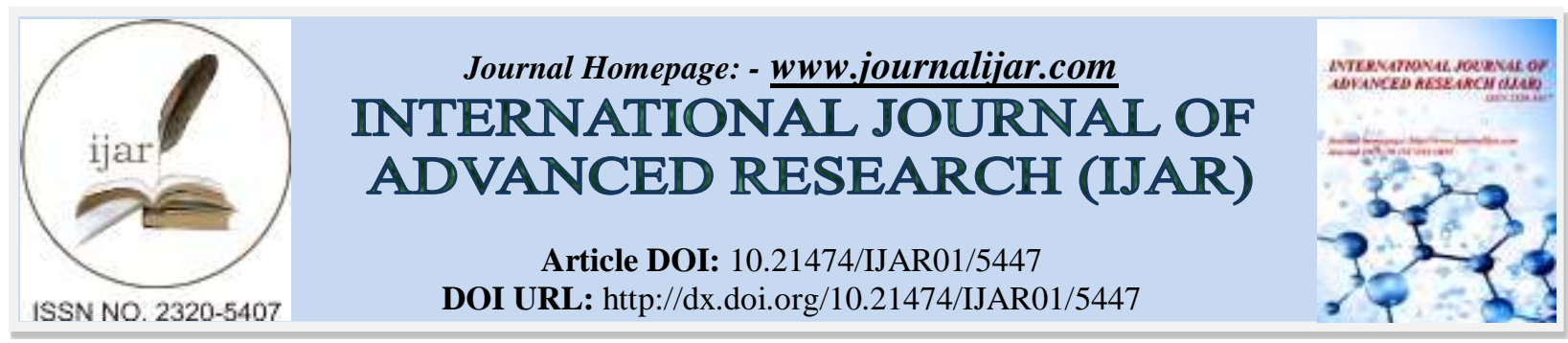

RESEARCH ARTICLE

\title{
CHEMICAL COMPOSITION OF CORDIA MYXA FRUIT: PHYTOCHEMICAL SCREENING AND IDENTIFICATION OF SOME BIOACTIVE COMPOUNDS.
}

1 The Gifted School of Basra, Basra, Iraq, 61001.

2 Dept. Chem. \& Marine Environ. Poll., Marine Science Center, University of Basrah, Basra, Iraq, 61001.

\section{Manuscript Info}

Manuscript History

Received: 16 July 2017

Final Accepted: 18 August 2017

Published: September 2017

Key words:-

GC-MS; Cordia myxa; phytochemical screening; traditional medicine; functional foods.

\section{Abstract}

Cordia myxa is a fruit grown around the globe for its nutritional and medicinal benefits. The identity and relative concentration of some compounds in the fruit extract was reported and preliminary phytochemical screening was performed. Ethanol extract was obtained by heated maceration using ethanol. The extract was screened for the presence of carbohydrates, proteins, glycosides, alkaloids, flavonoids, phenolic compounds, saponins, and tannins. Gas ChromatographyMass Spectroscopy was performed to identify the volatile compounds with their relative concentrations. The fruit was found to contain all tested compounds except saponins; and notable compounds identified with GC-MS include phytol, linoleic acid, olealdehyde, stigmastanol, $\gamma$ sitosterol, several esters and phosphate ester-derivatives, and a fatsoluble form of ascorbic acid. The study concludes that the fruit contain many bioactive compounds -with hyperlipidemic, hyperglycemic, cytotoxic, anti-inflammatory, and thyroid-inhibiting properties- but quantitative analysis is yet to be performed. More studies are needed to fully understand the chemical composition of the fruit - not just the volatile potion.

Copy Right, IJAR, 2017. All rights reserved.

\section{Introduction:-}

Plants have been used as medicines with qualities all over the world and for thousands of years. The study of the chemical composition and biological activities of these plants have received renewed scientific interest in the past few years [1].

Cordia myxa is a species of flowering plant in the borage family. The broad-leaved deciduous tree of Cordia myxa grows in many parts of the world, including tropical Africa, tropical Asia, the Americas, and the region stretching from eastern Mediterranean to eastern India [2-3].

The light pale fruit begins appearing in July-August, and tends to darken as ripening proceeds. When fully ripe, the translucent pulp, being full of mucilage, is quite sweet in taste [2-3].

The fruit is widely used in traditional medicine especially in the Middle east, India, and China. Due to certain demulcent properties, the fruit has been widely used to treat respiratory infections, coughing, and sore throat; also 
used as a diuretic. The pulp is used to mature abscesses, calm rheumatic pain, treat ringworm, and as an anthelminthic [2] [5-7].

Scientific literature indicates that Cordia myxa has certain analgesic, anti-inflammatory, immunomodulatory, antimicrobial, antiparasitic, insecticidal, cardiovascular, respiratory, gastrointestinal and protective effects [4] [8$10]$.

Prior studies have confirmed the presence of the nontoxic pyrrolizidine alkaloid macrophylline but no quantitative data is available. Moreover, Cordia myxa samples collected from the region have been found to contain trace amounts of 6 Polycyclic Aromatic Hydrocarbons (PAHs) with a total concentration 411.6 ng/g [12,13].

Cordia myxa fruit is regarded as a good source for fibers, proteins and carbohydrates, and some studies suggest promoting the fruit as a carbohydrate and protein supplement for cereal-based diets in poor rural communities [4].

The aim of the study was to perform preliminary phytochemical screening and identify some volatile compounds found in the fruit extract via Gas Chromatography-Mass Spectroscopy. Ethanol was chosen for its ability to extract the maximum plant constituents (flavonoids, alkaloids, tannins, glycosides, steroids, phenols, cardiac glycosides, saponins, carbohydrates, and proteins) compared with other solvents [14-16].

\section{Materials and Methods:- \\ Fruit Sample:-}

Cordia myxa was cultivated during August in Basra, Iraq. The fruit was identified by morphological comparison with traits described by AP database provided by Conservatory and Botanical Garden/ Geneva and South African National Biodiversity Institute.

\section{Extraction Method:-}

The extraction method was designed to extract maximum amount of bioactive compounds without altering thermosensitive and volatile compounds. The whole fruit was shade dried and pulverized to a powder using a Philips HL7720 mechanical grinder. The powder was immersed with ethanol absolute of $99.8 \%$ concentration and the extract heated to $70{ }^{\circ} \mathrm{C}$ with, stirring for 1 hour. Vacuum-filtration was performed drying over anhydrous sodium sulfate to remove traces of water. All materials were obtained from Sigma Aldrich.

\section{GC-MS Analysis:-}

A diluted volume of $8.00 \mu \mathrm{l}$ was injected in the system using AOC-20i/s auto-injector with split injection mode; injector temp. was $250{ }^{\circ} \mathrm{C}$. The test was run using a Shimadzu GCMS-QP2010 Ultra equipped with polar standard capillary column of $59 \mathrm{~m}$ length. Helium gas was used as the carrier gas with a total flow of $34.0 \mathrm{~mL} / \mathrm{min}$ (column flow of $1.00 \mathrm{~mL} / \mathrm{min})$. The oven temp. was programmed from $40 \circ \mathrm{C}(5 \mathrm{~min}$. hold time) to $180 \circ \mathrm{C}(1 \mathrm{~min}$ hold time) and to $300 \circ \mathrm{C}$ (5 min. hold time). The total running time was $37.0 \mathrm{~min}$. For the mass spectroscopic test, ion-source temp. was $200{ }^{\circ} \mathrm{C}$; solvent cut time was $3.00 \mathrm{~min}$; detector gain was $0.70 \mathrm{kV}$. Compounds were identified by their mass spectra and retention indices using the NIST Mass Spectral Library and the Retention Index Database. GCMS Insight Software Package was used to process the data.

\section{Phytochemical Qualitative Analysis:-}

Phytochemical screening for the following compounds was performed using standard methods [17]:

1. Carbohydrates: Extract was treated with Benedict's reagent and heated gently. Formation of orange red precipitate indicated a positive result.

2. Proteins: The extracts were treated with a few drops of concentrated nitric acid; yellow coloration of the sample indicates a positive result.

3. Glycosides: Extract was dissolved in bromine water; the formation of yellow precipitate which indicates a positive result.

4. Saponins: Extract was mixed with water and shaken; formation of froth that's stable for 15 minutes indicates a positive result.

5. Alkaloids: Extract was treated with few drops Wagner's reagent; precipitation indicates a positive result. Wagner's reagent was prepared by dissolving $2 \mathrm{~g}$ of iodine and $6 \mathrm{~g}$ of $\mathrm{KI}$ in $100 \mathrm{ml}$ of water.

6. Flavonoids: A few drops of Ferric chloride solution were added to the extract; the formation of dark red color indicates positive results. 
7. Phenolic compounds and tannins: Sodium hydroxide solution was added to the extract; the formation of yellow to red precipitate indicates a positive result.

\section{Results:-}

A total of 20 volatile compounds was identified in the extract using GC-MS analysis; their identities, retention indices (compared to a series of n-alkanes), and relative concentrations (percentage of area under the chromatogram) are shown in Table 1. In addition, the chromatogram is shown in Figure 1.

The highest identified concentration belongs to 1-(+)-Ascorbic acid 2,6-dihexadecanoate followed by - Octadecenal, (Z) and Hexadecanoic acid, 2-hydroxy-1-(hydroxymethyl) ethyl ester; with 9.94\%, 9.54\%, and 8.89\% respective concentrations. Phytol and Stigmasterol had lower concentrations of $6.38 \%$ and $5.86 \%$, respectively. Concentration of other compounds ranged between $2-5 \%$.

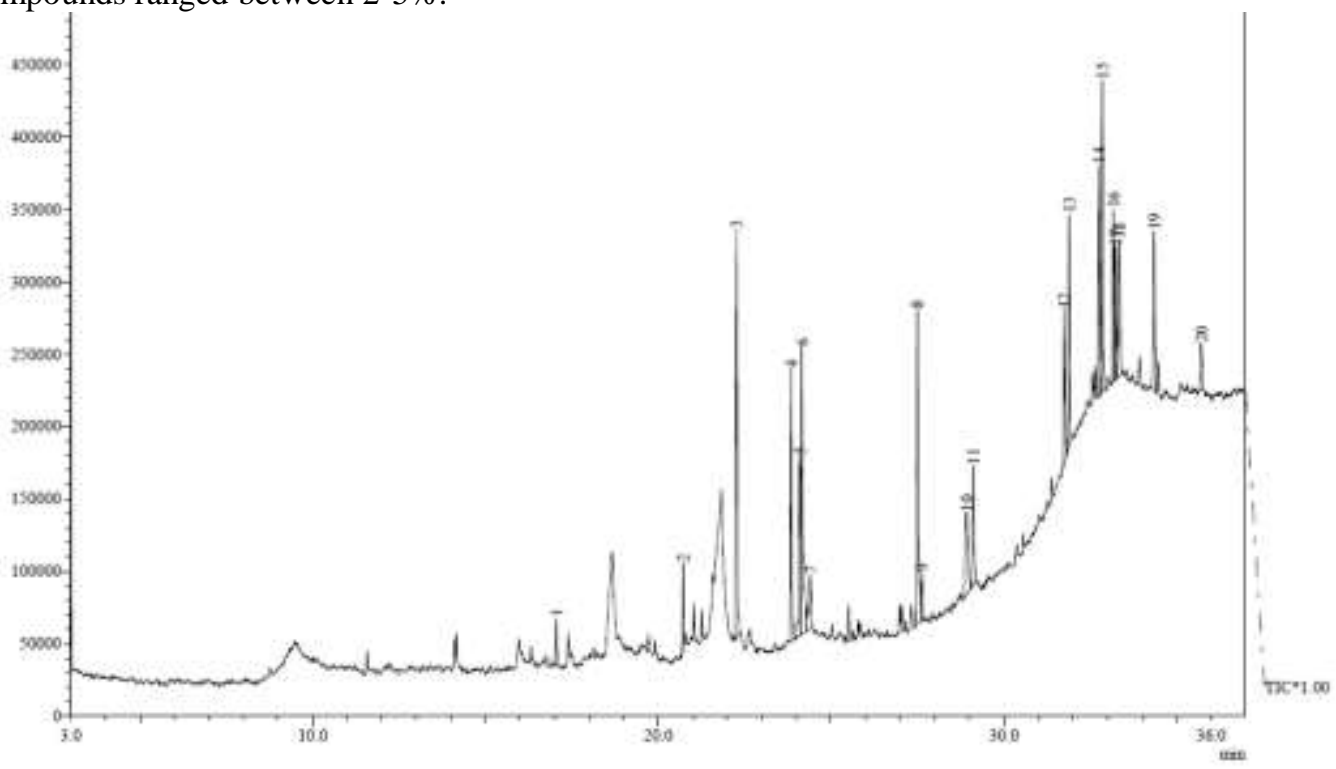

Figure 1:-GC-MS chromatogram for the ethanol extract of Cordia myxa fruit.

Table 1:-Description of identity and concentration of compounds identified with GC-MS.

\begin{tabular}{|c|c|c|}
\hline Name & RI* & $\mathbf{R C} * *(\%)$ \\
\hline Phosphoric acid, diethyl octyl ester & - & 0.99 \\
\hline 9-Octadecenal, (Z)- & 2007 & 9.54 \\
\hline 3,7,11,15-Tetramethyl-2-hexadecen-1-ol & 2045 & 1.87 \\
\hline Phytol & 2045 & 6.38 \\
\hline Oleoyl chloride & 2131 & 5.16 \\
\hline Octadecanoic acid & 2167 & 2.72 \\
\hline 9,12-Octadecadienoic acid (Z,Z)- & 2183 & 5.29 \\
\hline Hexadecanoic acid, 2-hydroxy-1-(hydroxymethyl)ethyl ester & 2498 & 8.89 \\
\hline Octadecanoic acid, 2,3-dihydroxypropyl ester & 2681 & 3.48 \\
\hline 1,2-Benzenedicarboxylic acid, diisooctyl ester & 2704 & 1.17 \\
\hline Cholestan-3-one, 4,4-dimethyl-, $(5 \alpha)$ - & 2704 & 8.25 \\
\hline Stigmastanol & 2720 & 4.86 \\
\hline$\gamma$-Sitosterol & 2731 & 3.46 \\
\hline Stigmasterol & 2739 & 5.86 \\
\hline 1-Heptacosanol & 2948 & 4.16 \\
\hline 1-Triacontanol & 3246 & 5.30 \\
\hline Dihydro-iso-solanidine 3,5-dinitrobenzoate & 4279 & 1.92 \\
\hline$\alpha$-Tocopherol- $\beta$-D-mannoside & 4489 & 5.43 \\
\hline 1-(+)-Ascorbic acid 2,6-dihexadecanoate & 4765 & 9.94 \\
\hline
\end{tabular}




\begin{tabular}{|l|l|}
\hline Total & 100.00 \\
\hline$*$ Retention Index (series of n-alkanes). & \\
$* *$ Relative Concentration (area \%) & \\
\hline
\end{tabular}

The preliminary phytochemical screening indicated the presence of carbohydrates, proteins, glycosides, alkaloids, flavonoids, phenolic compounds, and tannins. Saponins test produced a negative result.

\section{Discussion:-}

This study discusses the biological effects of some identified volatile compounds according to previous scientific literature, which might provide a preliminary reference for further studies regarding the importance of the fruit. The identified biologically-active ingredients of the fruit had a relative concentration falling between 3-8\%, except the fat-soluble form of ascorbic acid which accounted for around $10 \%$ of the identified portion.

A summary for the bioactivity of some identified compounds and their relative concentrations is provided in Table 2. Other active and inactive compounds were present in the extract; notably, stearic acid and several types of esters.

Table 2:- Bioactivity of some identified compounds and their relative concentrations

\begin{tabular}{|c|c|c|}
\hline Compound & Bioactivity & $\mathbf{R C}(\%)$ \\
\hline Stigmasterol & $\begin{array}{l}\text { (i) Prevents certain types of cancers including ovarian, prostate, breast, and colon } \\
\text { cancers. (ii) Posses certain antioxidant, hypoglycemic, hyperlipedimic, and thyroid } \\
\text { inhibiting properties. }[18,19]\end{array}$ & 5.86 \\
\hline Phytol & $\begin{array}{l}\text { (i) Posses certain cytotoxic effects on human HeLa cells and antiproliferative effects } \\
\text { on different types of human cells. (ii) An active anti-inflammatory agent. (iii) Linked } \\
\text { to regulating blood glucose and can possibly restore the metabolic functions of type } \\
\text { two diabetic patients. }[20,21]\end{array}$ & 6.38 \\
\hline Linoleic acid & $\begin{array}{l}\text { (i) Pro-inflammatory and anti-inflammatory effects. (ii) Helps in weight control. (iii) } \\
\text { Inhbits blood clottting inibitor (iv) Aids in the treatment of a broad-spectrum of } \\
\text { diseases. [22-33] }\end{array}$ & 5.28 \\
\hline $\begin{array}{l}\text { Phosphate } \\
\text { ester-deriv. }\end{array}$ & Enhance drug penetration through skin (emollient properties). & 0.99 \\
\hline Ascorbic acid & $\begin{array}{l}\text { (i) Must be ingested in human diet for survival. (ii) Linked to reduction of incidence of } \\
\text { cancer, regulating blood pressure, and enhancing immunity. (iii) Essential for drug } \\
\text { metabolism, urinary excretion, and tissue regeneration. (iv) Needed for enzymes } \\
\text { stimulation, collagen biosynthesis, hormonal activation, antioxidant activity, } \\
\text { detoxification of histamine, amongest others. [34] }\end{array}$ & 9.94 \\
\hline Olealdehyde & FAAH inhibition effects [35] & 5.16 \\
\hline Stigmastanol & $\begin{array}{l}\text { Hypolipidemic agent (lowers the levels of certain lipids in the blood and inhibit the } \\
\text { absorption of cholesterol from the diet) }[36,37] \text {. }\end{array}$ & 4.86 \\
\hline$\gamma$-Sitosterol & $\begin{array}{l}\text { Hypolipidemic agent (lowers the levels of certain lipids in the blood and inhibit the } \\
\text { absorption of cholesterol from the diet) [38]. }\end{array}$ & 3.46 \\
\hline
\end{tabular}

The phytochemical screening indicated the presence of many phytochemicals: carbohydrates, proteins, glycosides, alkaloids, flavonoids, phenolic compounds, and tannins. These results are consistent with previous scientific literature except that saponins were not detected [4].

The chemical composition of Cordia myxa fruit is not yet fully understood. More identification techniques are necessary to confirm the chemical composition of the fruit, notably HPLC (injecting with standards) and LC-NMR.

In conclusion, Cordia myxa fruit contains many bioactive compounds and can be part of a healthy diet. We suggest carrying out more studies to assess the bioactivity of the fruit, as well as more phytochemical studies.

\section{Acknowledgments:-}

The authors would like to acknowledge Dr. Dhiaa Al-Fekaiki for his help running the GC-MS test, and the deanship of the College of Agriculture/ University of Basra for providing permission and fee waiver. Ms. Zahraa Tuma (The Gifted School of Basra) is also acknowledged for lab assistance. 


\section{Conflicts of Interest:-}

The authors declare no conflict of interest.

\section{References:-}

1. Sathyaprabha, G., Kumaravel, S., Ruffina, D. and Praveenkumar, P. (2010): A comparative study on antioxidant, proximate analysis, antimicrobial activity and phytochemical analysis of Aloe vera and Cissus quadrangularis by GC-MS. J. Pharma., 2010. 3(3):29-70.

2. Schmelzer, G.H. and Gurib-Fakim, A (2008): Medicinal Plant 1. In: Plant resources of tropical Africa (Volume 11). Wageningen: Earthprint Limited, pp. 791.

3. Warfa AM (1988): Cordia (Boraginaceae). In: NE tropical Africa and tropical Arabia. Uppsla: Uppsla Univ., pp. 174.

4. Al-Snafi, AE (2017): The Pharmacological and therapeutic importance of Cordia myxa. IOSR Journal of Pharmacy, 6(6):47-57.

5. Rechinger, K.H (1997): Boraginaceae. In: Flora Iranica (Volume 48). Graz: Akademische Durck-u Verlangsantalt, pp. 6-10.

6. Al-Awadi, F.M., Srikumar, T.S., Anim, J.T. and Khan, I. Antiinflammatory effects of Cordia myxa fruit on experimentally induced colitis in rats. Nutrition, 17(5):391-396.

7. Alami, R. and Macksad, A. (1974). Medicinal plants in Kuwait (Volume 6). Kuwait: Al-Assriya Press Volume, pp. 50-137.

8. Rashed, K., Luo, M.T., Zhang, L.T., and Zheng, Y.T (2015): Evaluation of anti-HIV-1 activity of Cordia myxa L., and phytochemical profile. Banat's Journal of Biotechnology, 5(10):75-82.

9. Pandey, B., Deshpand, B., Singh, S., and Chandrakar, V. (2014): Estimation of elemental contents of Cordia myxa and its antimicrobial activity against various pathogenic microorganisms. Indian J. Sci. Res., 4(1):39-44.

10. Abdallah, I.A., Khattab, H.H., and Heeba, G.H (2011): Gastroprotective effect of Cordia myxa L. fruit extract against indomethacin-induced gastric ulceration in rats. Life Science Journal, 8(3):433-445.

11. Ali, K.A. (2008): Study of effect of alcoholic extract of fruit of Cordia myxa in total count and differential count of white blood cells in rats. Al-Qadisyia Journal of Vet. Med. Sci., 7(2):21-24, .

12. Aberoumand, A. (2011): Preliminary evaluation of Some phytochemical and nutrients constituents of Iranian Cordia myxa fruits. IJAFST, 1(2):30-33.

13. Shwaish, T.Z. and Al-Imarah, F.J. (2016): Chromatographic Study of the Ethanol Extract of Cordia myxa L. Fruit. J Pharm Chem Biol Sci., 4(2):142-152.

14. Nishaa, S., Vishnupriya, M., Sasikumar, J.M., and Gopalakrishnan, V.K (2013): Phytochemical screening and GC-MS Analysis of ethanolic extract of rhizomes of Maranta arundinacea L. Res. J. Pharm. Biol. Chem. Sci., 4(2):52-59.

15. National Center for Biotechnology Information (2017): Pub Chem Compound Database (CID=702). Available online: https://pubchem.ncbi.nlm.nih.gov/compound/702 (accessed 11 March 2017).

16. Lapornik, B., Prošek, M., and Wondra, G (2005). Comparison of extracts prepared from plant by-products using different solvents and extraction time. J. Food Eng., 71(2):214-222.

17. Tiwari, P., Kumar, B., Kaur, M. Kaur, G, and Kaur, H. (2011): Phytochemical screening and Extraction: A Review. Internationale Pharmaceutica Sciencia, 1:98-106.

18. Woyengo, T.A., Ramprasath, V.R., Jones, P.H. (2009): Anticancer effects of phytosterols. European Journal of Clinical Nutrition, 63:813-820.

19. Panda, S., Jafri, M., Kar, A., and Meheta, B.K. (2009): Thyroid inhibitory, antiperoxidative and hypoglycemic effects of stigmasterol isolated from Butea monosperma. Fitoterapia, 80(2):123-126.

20. National Center for Biotechnology Information (2017). PubChem Compound Database (CID=5280435). Available online: https://pubchem.ncbi.nlm.nih.gov/compound/5280435 (accessed 5 March 2017).

21. Elmazar, M. M., El-Abhar, H. S., Schaalan, M. F., and Farag, N. A. (2013): Phytol/Phytanic Acid and Insulin Resistance: Potential Role of Phytanic Acid Proven by Docking Simulation and Modulation of Biochemical Alterations. PLoS ONE, 8(1):e45638.

22. Johnson, G.H., and Fritsche, K. Effect of dietary linoleic acid on markers of inflammation in healthy persons: a systematic review of randomized controlled trials. J. Acad. Nutr. Diet, 112(7):1029-41.

23. Attar-Bashi, N.M., Li, D., and Sinclair, A.J. (2004): Alpha-linolenic acid and the risk of prostate cancer. Lipids, 39(9):929-32.

24. Harris, W. (2010): Omega-6 and omega-3 fatty acids: partners in prevention. Curr. Opin. Clin. Nutr. Metab. Care, 13(2):125-9. 
25. Kast, R.E. (2001): Borage oil reduction of rheumatoid arthritis activity may be mediated by increased cAMP that suppresses tumor necrosis factor-alpha. Int. Immunopharmacol., 1(12):2197-2199.

26. Kenny, F.S., Pinder, S.E., Ellis, I.O, Bryce, R.P., Hartley, J., and Robertson, J.R. Gamma linolenic acid with tamoxifen as primary therapy in breast cancer. Int. J. Cancer, 85:643-648.

27. Kupferer, E.M., Dormire, S.L., and Becker, H. (2009): Complementary and alternative medicine use for vasomotor symptoms among women who have discontinued hormone therapy. J. Obstet. Gynecol. Neonatal Nurs., 38(1):50-9.

28. Manjari, V., and Das, N. Effect of polyunsaturated fatty acids on dexamethasone-induced gastric mucosal damage. Prostaglandins Leukot. Essent. Fatty Acids, 62(2):85-96.

29. Menendez, J.A., del Mar Barbacid, M., Montero, S., Sevilla, E., Escrich, E., Solanas, M., Cortés-Funes, H., and Colomer, R. (2011): Effects of gamma-linolenic acid and oleic acid on paclitaxel cytotoxicity in human breast cancer cells. Eur. J. Cancer, 37:402-413.

30. Richardson, A.J. and Puri, B.K. (2000): The potential role of fatty acids in attention-deficit/hyperactivity disorder. Prostaglandins Leukot. Essent. Fatty Acids, 63(1/2):79-87.

31. Schirmer, M.A. and Phinney, S.D. Gamma-linolenate reduces weight regain in formerly obese humans. $J$. Nutr., 137(6):1430-5.

32. Weaver, K.L., Ivester, P., Seeds, M., Case, L.D., Arm, J.P., and Chilton, F.H. Effect of Dietary Fatty Acids on Inflammatory Gene Expression in Healthy Humans. J. Biol. Chem., 284(23):15400-15407.

33. Worm, M. and Henz, B.M. (2000): Novel unconventional therapeutic approaches to atopic eczema. Dermatology, 201(3):191-195.

34. Walingo, K.M (2005). Role of vitamin C (ascorbic acid) on human health- a review. AJFAND, 5(1):1-11.

35. National Center for Biotechnology Information (2017). PubChem Compound Database (CID=5364492). Available online: https://pubchem.ncbi.nlm.nih.gov/compound/5364492 (accessed 15 March 2017).

36. Batta, A.K., Xu, G., Honda, A., Miyazaki, T., and Salen, G. (2006): Stigmasterol reduces plasma cholesterol levels and inhibits hepatic synthesis and intestinal absorption in the rat. Metabolism, 55(3):292-299.

37. Heinemann, T., Pietruck, B., Kullak-Ublick, G., and von Bergmann, K. Comparison of sitosterol and sitostanol on inhibition of intestinal cholesterol absorption. Agents and actions. Supplements, 26: 117-122.

38. Heinemann, T., Kullak-Ublick, G.A., Pietruck, B., and von Bergmann, K (1991): Mechanisms of action of plant sterols on inhibition of cholesterol absorption. Comparison of sitosterol and sitostanol. Eur. J. Clin. Pharmacol. 40 (Suppl 1):S59-63. 